\title{
JOHN SOANE, ARQUITECTO DEL ESPACIO Y LA LUZ
}

\author{
Pedro Moleón *
}

A propósito de la exposición celebrada bajo este título en la Real Academia de Bellas Artes de San Fernando (Madrid, 6 de noviembre-14 de diciembre de 200I)

$\mathrm{L}$ a obra del inglés John Soane forma parte de lo que la moderna historiografía de la arquitectura ha calificado como clasicisimo romántico. Fue un arquitecto e historiador británico quien acuñó esta fórmula, aparentemente contradictoria en sus términos, para poder explicar un ciclo artístico que encuentra los motivos para la creación tanto en la razón como en el impulso emocional. La expresión aparece por primera vez en el libro de Geoffrey Scott: The Architecture of Humanism (1914), en el que se lee: «Un clasicismo romántico hecho de sentimiento, y reflexión ha cubierto y apagado el clasicismo creador nacido en el quatrocento y que había mantenido su dominio hasta entonces»!

\footnotetext{
* Pedro Moleón, es comisario de la exposición, además de autor del libro John Soane (1753-1837) y la arquitectura de la razón poética (Mairea, Madrid, 2001) que introduce el texto aqui publicado.
}

La fórmula confirma su sentido y se consolida al ser parte del título del libro de Sigfried Giedeon: Spátbarocker und romantischer Klassizismus (1922), en el que su autor distingue los rasgos diferenciales existentes entre un tardobarroco clasicista y un clasicismo romántico, reconocible este último, en relación con la arquitectura alemana partir del momento a Federico el Grande proyectado por Fiedrich Gilly en $1796^{2}$ «Romantic-Classicism in Architecture» es el título de un célebre ensayo de Fiske Kimball, publicado en la Gazette des Beaux Arts en 1944, y la expresión es común también en los textos de historiadores de diferentes orígenes, como $\mathrm{N}$. Pevsner y H. R. Hitchcock. Hugh Honour, por su parte, considera la fórmula un híbrido insostenible, aunque no puede dejar de admitir, coincidiendo con G. Scott, que «el movimiento neoclásico contenía en sí mismo las semillas de la mayoría de las fuerzas románticas que lo destruirían.»3 
Retomando de nuevo la definición inicial, en una bipolaridad hecha de razón y sentimiento está, para el clasicismo romántico, el germen de la creación artística, que se nutre tanto de, lo intelectual como de lo emocional, de lo reflexivo como de lo afectivo, para hacer aflorar en sus obras la juiciosa libertad que sabe someterse a las reglas del arte y al capricho de una espontaneidad sin trabas. Tal doble polaridad operativa se puede deducir en los textos y en las realizaciones de los mejores arquitectos de la segunda mitad del siglo XVIII sin entenderla necesariamente como una dualidad de motivos enfrentados o mutuamente excluyentes, sino como estados de ánimo, como par de fuerzas o, mejor, como momentos, a veces sucesivos, a veces simultáneos, pero siempre compatibles, del proceso de concebir y realizar la obra artística, así como del modo de recibirla y valorarla. Y en todo ello, inevitablemente, el punto de vista del sujeto, sea artista o receptor, su posición en el mundo, su horizonte, su fondo de perspectiva, desempeñan un papel decisivo.

La conciencia de una subjetividad desde la cual acceder al conocimiento y a la comprensión de la realidad cornienza a producir textos filosóficos ya en la primera mitad del siglo XVII y llega al terreno específico del arte y la literatura en las posturas enfrentadas en la famosa querelle entre antiguos y modernos de la Francia de Luis XIV, a propósito de la concepción de una belleza positiva -que es absoluta, objetiva, universal, convincente y necesaria- y de una belleza arbitraria -relativa, subjetiva, individual, convenida y contingente- , resultado del encuentro entre la obra y su destinatario y cuya valoración depende de la predisposición, la costumbre, la moda y la conexión o afinidad espiritual que se dé entre autor y receptor. Es entonces cuando se hace patente la conciencia de un subjetivisimo innegable en el juicio estético y de un subjetivismo irrenunciable en los procesos de creación artística, una conciencia que ya en el Siglo de las Luces ha asumido el rango de creencia unánimemente aceptada.

Esa conciencia de época, que podemos considerar plenamente actual, nos lleva a plantearnos de qué modo la subjetividad afecta al proceso de creación artística, de qué modo el arquitecto la traslada a su obra, que finalmente expresa y comunica sus motivos para que sean interpretados por quienes la reciben. Éste es quizá el gran argumento de la obra de Soane, el mismo que marca la producción de los mejores arquitectos del clasicismo romántico que lanza sus puentes entre los siglos XVIII y XIX. En este sentido, si el estudio de la producción soaniana nos sitúa ante una arquitectura inseparable de la línea de continuidad de la tradición clásica iniciada en el quattrocento italiano, no es menos cierto que nos sitúa también ante un hombre empeñado a toda costa en que su obra trascendiera su propia vida, ante un hombre dotado de una sólida capacidad reflexiva y analítica que no anula, sino que, por el contrario, alienta las cualidades sentimentales de su carácter. Un, perfil psicológico como éste lleva consigo, casi inevitablemente, que su obra sea antes el producto de una libre voluntad artística que la respuesta disciplinada a una necesidad programática. Dicho de otro, modo, la obra de 
Soane es fiel reflejo de su personalidad no sólo como resultado, sino también como meta, y es también uno de los mejores ejemplos posibles de la manera en que un arquitecto es capaz de doblegar los requerimientos funcionales que condicionan un encargo para traducir la necesidad en deseo y el deseo en libertad para crear.

En Soane las cosas no son nunca de un modo único, inequívoco, ni responden con claridad a un estatuto formal, intencional e ideológico, fácilmente catalogable. La misma clasificación de su obra dentro de los supuestos o actitudes del clasicismo romántico nos habla de la necesidad de matices y fórmulas complejas para encajarla en un corsé estilístico. $Y$ todas sus manifestaciones artísticas responden al mismo patrón ambivalente: sus bóvedas vaídas más características son a la vez cúpulas rebajadas sobre pechinas; otras de doble arista, igualmente asociables con su estilo, tienen algo de romanas y a la vez algo del espiritu del gótico. La ambición posesiva del anticuario y la voluntad de comprensión del arqueólogo dirigen simultáneamente su vocación de coleccionista. La luz natural y la artificial, la luz directa y la luz reflejada, la luz lateral la luz cenital coexisten en su obra en la búsqueda de efectos emotivos. Todo en Soane parece aspirar a la conciliación de contrarios en un principio único omnicomprensivo. Su perfil ideal del arquitecto demanda de éste una actitud de poeta, pintor y escultor ante la obra, buscando la superación de las barreras entre los distintos saberes específicos, mediante la unión de la filosofía, las ciencias y todas las artes, con el fin de acen- tuar lo velado, lo misterioso, lo evocador, lo implícito, lo inconmensurable, es decir, con el fin de poetizarlo todo, contaminando con un aire nuevo de patetismo y carga emocional, los principios del clasicismo, que nacen, para él, tanto de la razón como del sentimiento.

Razón y pasión no fueron nunca para Soane, como no lo fueron tampoco para Piranesi o Ledoux, para Le Camus, de Mézières o Boullée, principios opuestos, enfrentados o mutuamente excluyentes a la hora de concebir la arquitectura como un arte de invención orgulloso de su originalidad. Todos ellos aspiraron a una especie de identificación de tales contrarios en un mismo principio creador. $\mathrm{Y}$ precisamente en el hecho de no encontrar contradicción entre ellos, junto al factor de simultaneidad o de coexistencia de ambos motivos en sus obras, podríamos cifrar su libertad artística hasta la consecución de una espontaneidad -creadora y vital-hecha estilo.

Si intentáramos una valoración actual de la obra de Soane, quizá la mejor observación para iniciarla la encontraríarnos en las declaraciones del arquitecto americano Philip Johnson en una entrevista de 1986: «... en realidad [Soane] es un arquitecto de techos. Con esto no estoy tratando de menospreciarlo. Cuando se piensa en la propia experiencia actual de los techos, se quiere decir pared, techo, envolvenle y luz» ${ }^{4}$. Cabría añadir, para afinar el alcance del comentario interior, que pared, techo, envolvente y luz son los miembros fundanlentales del espacio arquitectóníco, tanto de su estructura fomal como de su atmósfera y sus cualidades interiores. Es más, la sinécdoque con la que Philip Johnson se 
refiere al espacio arquitectónico, al dentro acotado que se opone a un fuera abierto, nombrándolo simplemente como techo, está en el origen del arte y es constante que el techo seit, así entendido, sinónimo de cobijo y resguardo como contrario radical de la intemperie, y que tanto la cueva como la tienda o la cabaña primitivas posean la principal virtud de aportar un techo habitable para la vida de las culturas de hombres cazadores, pastores o agricultores, respectivamente. Las paredes, los muros, elementos a los que nadie negaría su capacidad protectora, no son suficientes para instituir la más elemental idea de la arquitectura. Como sinécdoque podríamos tomar muros y paredes por prisión, caso particular y poco atractivo del espacio para la vida, sin la componente generalista de evocación de toda arquitectura que tiene el techo.

Desde Alberti, es decir, desde el momento inaugural de la teoría moderna de la disciplina, está escrito que nuestros antepasados concedían al techo tal importancia que casi llegaron a agotar todas las artes decorativas en su ornamentación. Generador incluso del resto de los elementos constituyentes, «la techumbre fue por su naturaleza la primera de todas las construcciones $[\ldots]$ a causa de la techumbre se inventaron no sólo los muros, y cuantas cosas nacen con los muros vienen a continuación de ellos, sino también aquellos elementos que van bajo el mismo suelo». Argumento que recoge también la tradición vitruviana al exponer que «en todo edificio no es menester más que un techo y quien lo sostenga ${ }^{5}$ otorgando así al techo una preeminencia fundacional de la idea de arquitectura y a su soporte un sentido más propiamente instrumental incluso sobreentendido, aunque también esencial.

Tras la afirmación de Philip Johnson, sabemos ya, de partida, que Soane es arquitecto de techos. De la estirpe, podríamos añadir ahora, de Alvar Aalto o Louis Kahn, que confían también al techo, como cierre espacial, cualidades esenciales de atmósfera y luz en la arquitectura. Consecuentemente, el último gran libro que se ha dedicado a la obra de Soane lo define como maestro del espacio y la luz. $Y$ en efecto, sus espacios de dobles y triples alturas tienden a incorporar en diferentes estratos e intensidades los diferentes efectos expresivos de la luz -natural, filtrada tamizada, coloreada, reflejada, cenital, lateral, misteriosa- y la sombra - desde la oscuridad a todos los grados imaginables de penumbra-, e incluso ese caso particular de la iluminación interior en el que también Soane fue maestro: el de la luz artificial.

Pero Soane es más cosas. Su obra ejemplifica como ninguna lo que él mismo denominaba $l a$ poesía de la arquitectura y da forma material, tangible y envolvente, a lo, que otros arquitectos de su época, singularmente Boullée y su arquitectura de las sombras, sólo pudieron dejar representado sobre el papel. Soane se revela así como una suerte de arquitecto poeta y, citando a Louis Kaln, «no conozco mayor elogio para un arquitecto que decir de él que es un poeta». Podríamos afirmar, por tanto, que la arquitectura de Soane es la arquitectura de la razón poética, como, la de su contemporáneo, el prusiano Karl Friedrich Schinkel (1781-1841) es la arquitectura de la razón constructiva. Para explicar esto un poco, basta recordar que Schin- 
kel dejó escrito en su Lehrbuch, el famoso manual que pasó la vida escribiendo y revisando: «las formas pueden ser cualesquiera, pero deben ser pensadas contructivamente» ${ }^{7} \mathrm{y}$ en otro lugar del mismo manuscrito, Schinkel sostiene: «Toda forma arquitectónica de una obra plenamente conseguida ha de dar siempre noticia de que se basa en un sistema estructural claro previamente desarrollado, del que se obtiene una completa articulación» ${ }^{8}$.

Construcción lógica de la arquitectura, sometimiento de la obra al dogma tectónico, sistemas estructurales y constructivos que condicionan concepciones espaciales, nuevos materiales, en estos principios encuentra sus motivos dominantes la obra de Schinkel -motivos de los que Soane nunca hizo bandera, aunque también estén presentes en su obra-, hasta el punto de que el historiador de la arquitectura Julius Posener llega a afirmar: «Pevsner ha dicho de los trabajos de Soane que se refleja en ellos la nueva actitud frente a la técnica. Yo no he podido encontrar esta relación en la obra de Soane, en cambio en el trabajo de Schinkel esta observación es atinada.»"

Soane y Schinkel no se conocieron ni se influyeron mutuamente, pero confrontarlos es útil porque representan concepciones complementarias de idéntica pasión por la arquitectura. Entre ambos hay un salto de dos generaciones históricas, aunque murieron con poco más de cuatro años de diferencia, Soane longevo, Schinkel en un momento de madurez para un arquitecto. Ese salto generacional influye grandemente en nuestra actual valoración de sus respectivas obras.
Por su comprensión de la arquitectura como expresión artística del sentimiento y espejo del espíritu que la concibe, Soane es el mejor último representante de los principios de la fustración en la que se formó, es un fin de raza, cierra una época. Schinkel, por su parte, entendía la arquitectura como expresión de una lógica tectónica -estructural y constructiva- prioritaria en la obra, y lo hace así en un momento en el que nuevas técnicas y nuevos materiales iban a revolucionar los principos artísticos, el lenguaje simbólico y los repertorios formales de la arquitectura. En consecuencia, Schinkel es un hombre puente entre dos épocas, tiene otra formación y cree en otras cosas que Soane, es un precursor que anticipa en su obra, especialmente la de la última etapa, lo que otros harán mejor que él, aunque él ya hubiera empezado a hacerlo.

Decía más arriba que Soane y Schinkel no se conocieron, aunque en el viaje de Schinkel a Francia e Inglaterra en 1826, el prusiano visitó el domingo 11 de junio la casa del inglés y sobre ella anotó en su diario:

«Como todas las casas particulares de Londres, ésta es pequeña, sin embargo contiene un gran número de vaciados, fragmentos de esculturas y edificios, vasos, sarcófagos, paneles y bronces, todo expuesto de la manera más ingeniosa en salas diminutas, iluminadas cenital y lateralmente, comúnmente de sólo 3 pies de ancho. Obras medievales, antiguas y modernas están intercaladas en todos los niveles; en los patios se simulan cementerios y en las habitaciones [hay] capillas, catacumbas y salas, decoradas en estilos gótico y herculanense. En todas partes pequeñas decepciones» ${ }^{10}$. 
Por la última observación deducimos que no le gustó la casa de Soane a Schinkel, que quedó más agradablemente impresionado en Londres por la principesca mansión de John Nash, en Regent Street, e incluso hizo un dibujo en perspectiva de su galería-biblioteca, anotando materiales y acabados de la sala. No supo ver en la casa de Soane una arquitectura concebida, de. un modo intencional y programático, como expresión artística; una arquitectura dirigida a contagiar a quien la visita los mismos poderes de evocación que el arquitecto empleara en su creación. Una arquitectura con la fantasía y el genio comprimidos en su interior, dirigida fundamentalmente a la mirada y sugeridora de imágenes y atmósferas asociadas, llena de aquellos caprichosos, variados y cambiantes efectos que constituyen la poesía de la arquitectura. De hecho, una motivación artística como ésta es la que finalmente Schinkel parece echar de menos en su propia obra cuando, recapitulando sobre ella, escribe:

«Casi sin darme cuenta incurrí en el error de una abstracción puramente radical, desarrollando el proyecto completo de una determinada obra arquitectónica partiendo únicamente de su más obvia finalidad utilitarista y de la construcción; se creaba así algo árido, falto de libertad y que excluía totalmente dos elementos esenciales: la historia y la poesía»".

Como ya hemos visto, Julius Posener citaba a su compatriota Nikolaus Pevsner para contradecir la lectura de Soane que el segundo hacía en clave tecnicista. Vale la pena, en desagravio, recordar de nuevo a Pevsner, aunque en reflexiones más generales, cuando afirma en la introducción a su libro An Outline of European Architecture (1943): «el término arquitectura se aplica exclusivaniente a edificios proyectados con el propósito de suscitar una emoción estética», para encargarse a continuación de explicar las tres maneras distintas en que un edificio puede provocar tal afección del ánimo: en la primera, la arquitectura se expresa mediante el tratamiento de los muros, las proporciones y la ornamentación, ésta es para Pevsner la manera bidimensional propia del pintor. En la segunda, la expresión de la arquitectura se consigue jugando a contrastar los volúmenes exteriores y sus juegos de entrantes y salientes; es la manera plástica y tridimensional del escultor, nos dice Pevsner. Finalmente, «en tercer lugar; hay, el efecto que nos produce en los sentidos la concepción y manera de tratar el interior». Esta tercera forma de expresión tiene también, como la anterior, un estatuto tridimensional, pero, escribe Pevsner, «se refiere al espacio; más que las otras es propia del arquitecto. Lo quediferencia la arquitectura de la pintura y de la escultura es su sentido espacial. En esto, y sólo en esto, ningún otro artista puede emular al arquitecto.» ${ }^{12}$

La explicación de Pevsner, clara y sencilla, sobre qué es arquitectura y cómo consigue aquel efecto emotivo que la distingue de la mera construcción, tiene un atractivo añadido en relación con los motivos de la entera obra de Soane, ya que éste mantenía que sólo de la unión de la poesía, la pintura, la escultura y la arquitectura se obtendrá la obra total, y lo hacía con argumentos muy parecidos a los de Pevsner, dominados todos por la razón poé- 
tica de una arquitectura narrativa, expresiva, evocadora y alusiva, que, cargada de emoción ella misma, habla a la imaginación cuando cuenta su propia historia.

\section{NOTAS}

' Citado de Geoffrey Scott: La arquitectura del Humanismo. Un estudio sobre la historia del gusto. Barcelona. Barral, 1970. pág. 49.

${ }^{2}$ Cfr. Georges Teyssot: «Clasicismo. Neoclasicismo y Arquitectura revolucionaria», en Emil Kaufmann: Tres arquitectos revolucionarios: Boullè, Ledoux y Lequeu [1952]. Barcelona, GG, 1980. págs.15-35.

${ }^{3}$ Hugh Honour: Neoclasicismo [1968]. Madrid. Xarait, 1982. pág. 214-216.

4 «... wall, ceiling, enclosare and light». Citado en Giles Waterfield: Soane and after. The Arquitecture of Dulwich Picture Gallery (catálogo de la exposición). Londres, Dulwich Picture Gallery, 1987. pág. 93.

${ }^{5}$ Leon Battista Alberti: De Re Aedificatoria [1485]. II. I. citado por la edición de Madrid. Akal, 1991. pág. 95 y José Ortiz y Sanz: Instituciones de arquitectura civil acomodadas en lo posible a la doctrina de Vitruvio [1819]. Ed. facsímil. Madrid, COAM, 1990, párrafo 32.

'Véase Louis 1, Kahn: Writings, Lectures, Interviews. Nueva York, Rizzoli, 1991. pág. 334.

7 J. Posener: «El manual de arquitectura de Schinkel», en
J. M. García Roig (ed.): K.F. Schinkel. Madrid ETSAM, 1991. págs. 17-18.

" J. Posener: «El manual de arquitectura de Schinkel», en J.M. García Roig (ed.): K.F. Schinkel. Madrid, ETSAM, 1991. pág. 75.

'J. Posener: op. cit., pág. 73.

${ }^{10}$ Véase David Bindman y Gottfried Riemann (eds.): Karl Friedich Schikel "The English Journey". Journal of the Visit to France an Britain in 1826. New Haven and London, Paul Mellon Centre Yale University Press, 1993. pág. 114.

"El texto sigue: "Continué indagando hasta qué punto el principio racional podría ser efectivo para fijar el concepto trivial del objeto y hasta qué punto, por otra parte, debería dar rienda suelta a aquellos nobles influjos de los objetivos artísticos y poéticos con el fin de elevar la obra de arquitectura a su condición de arte" Citado en Simón Marchán: «Las arquitecturas del clasicismo romántico», en Schinkel: arquitecturas (1781-1841). Madrid, MOPU, 1981. p.41.

${ }^{12}$ Citado de Nikolaus Pevsner: Esquema de la arquitectura europea. Buenos Aires, Infinito, 1968. $2^{\mathrm{a}}$ ed. pág. 17.

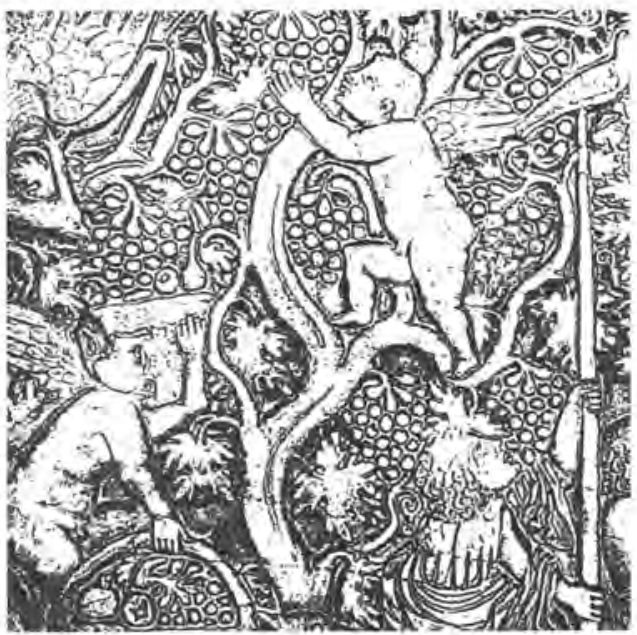




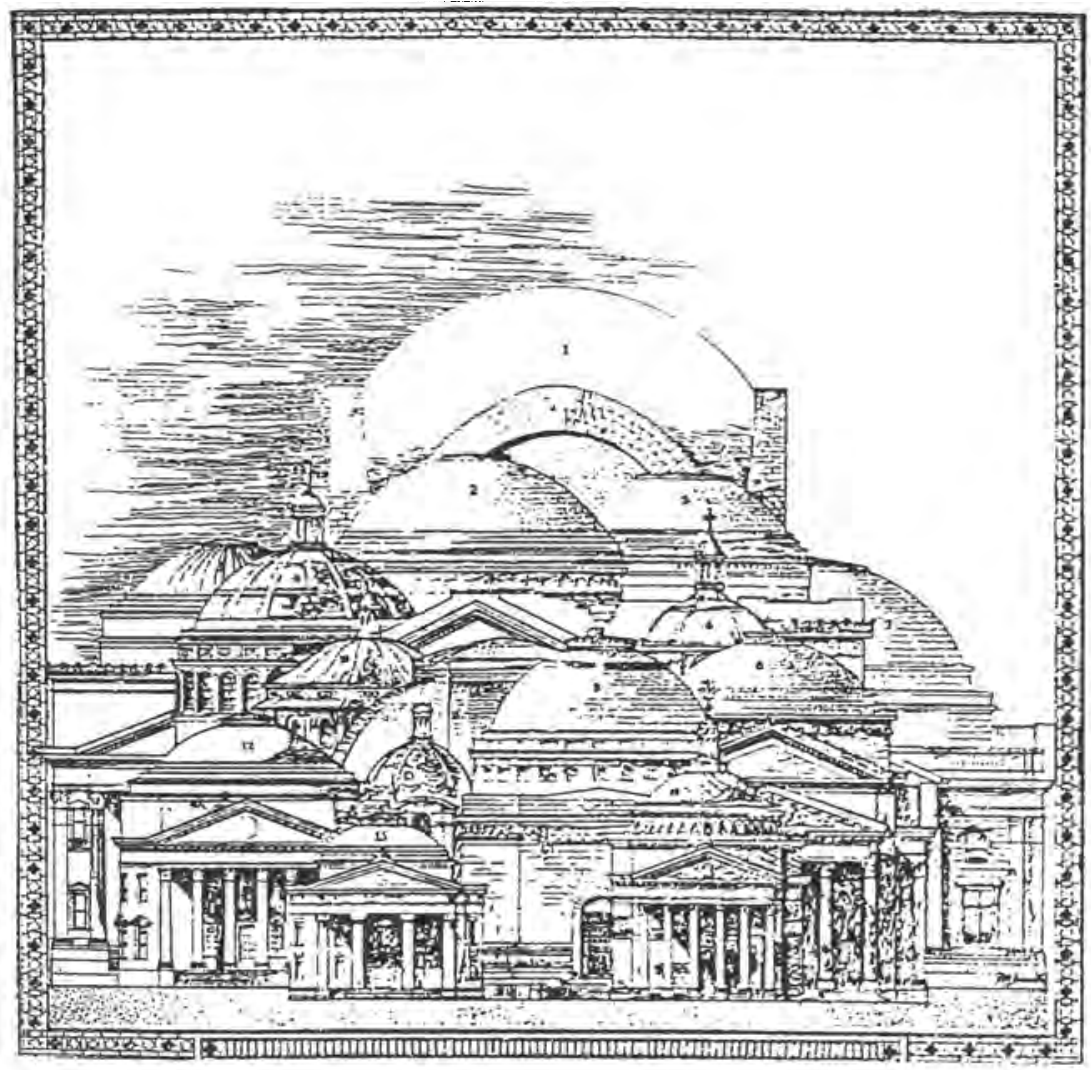

Algunas cúpulas construidas por la Compañía Guastavino entre 1897 y 1911. Este dibujo llegó a ser la marca de la empresa. 